\title{
Interactive comment on "New particle formation in the sulfuric acid-dimethy lamine-water system: Reevaluation of CLOUD chamber measurements and comparison to an aerosol nucleation and growth model” by Andreas Kürten et al.
}

\section{Anonymous Referee \#1}

Received and published: 13 October 2017

This paper presents revised calculations of nucleation rate of CLOUD7 ternary nucleation of sulfuric acid-dimethyl amine-water $(278 \mathrm{~K}, 38 \% \mathrm{RH}$, sulfuric acid concentration between $1 \mathrm{e} 6$ and $3 \mathrm{e} 7 \mathrm{~cm}-3$ and dimethylamine mixing ratio of $\sim 40 \mathrm{pptv}$; shown in Almeida et al., Nature 2013), and concludes that under this base-dominant and low temperature conditions, DMA-THN takes place in kinetic regime, that is, collisionlimited coagulation of clusters (without nucleation barrier; and no effects of evaporation rates for H2SO4-DMA). The conditions with high concentrations of DMA and low temperatures seem to be plausible for barrier-less nucleation, although it is still difficult 
to conclude this with limited knowledge of thermodynamics of nucleation (e.g., BHN, THN or IIN). This recalculation is useful to the community. I suggest to tone down other conclusions and remove the simulation of atmospheric NPF with low amines (Section 3.6), as described below.

The authors conclude that the CLOUD7 results are consistent with Jen et al. ACP 2016 flow tube THN experiments; the latter was undertaken at a high temperature and acidic conditions ( $6 \mathrm{e} 9 \mathrm{~cm}-3$, tens of pptv of amines, and near $300 \mathrm{~K})$. If they both take place via the same collision-limited coagulation processes, this is most likely because of very different reasons. For CLOUD7, this is due to low temperature and high DMA. And for Jen et al., this is due to exceedingly high sulfuric acid (so that nucleation rates are sensitively dependent on base concentrations). To show they are consistent, the best way is to use the current nucleation algorithm to re-calculate nucleation rates using the experimental data from Jen et al. If even 0,1 pptv DMA makes nucleation kinetic (at both acidic and basic conditions and both low and high temperatures), then di-amines (Jen et al., GRL 2016) should not further enhance nucleation rates, which is not the case. Also, ammonia and amines also should not enhance nucleation (Yu et al., GRL 2012; Glasoe et al., JGR 2015). So, this is an overstatement: "using this model, the findings from the present study and the flow tube experiment can be brought into good agreement."

The authors also conclude that in the boundary layer (temperature $>245 \mathrm{~K}$ ), even with $0.1 \mathrm{ppt}$ level of dimethylamine, nucleation would proceed with the collision limited process. The section 3.6 is too speculative and should be removed - see below minor comments in detail, to improve the paper quality.

Note, DMA is the only amine that so far CLOUD used and published, but there are other amines that can be as effective as DMA as ternary species, such as trimethylamine (Yu et al., GRL 2012; Glasoe JGR 2015; Jen GRL 2016; Hanson et al., JPC 2017), diamines (Jen GRL 2016) and even methylamine (Chen et al., EST 2017; Chen et al., JPC 2016). And these amines are present in almost everywhere in our environment at

Printer-friendly version

Discussion paper 2 
anytime, especially within the boundary layer.

Also, some assumptions used in this study have apparent limitations (in addition to ACPD evaporation rates at $247 \mathrm{~K}$ ). For example. $\mathrm{RH}$ has significant effects on both nucleation and growth rates of sub-3 $\mathrm{nm}$ particles, as shown by flow tube experiments, even within a wide range of temperatures covering both CLOUD7 and Jen et al. conditions (Yu et al., 2014). Yu et all also showed that growth rates are not constant within the sub-3 nm particle size.

Please provide detailed tables of variables/values/sources used in models in supporting material, including evaporation rates for clusters.

Please remove redundant sentences.

Line 66: At the surface level, in fact sulfuric acid can be as high the conditions of CLOUD7 (very frequently), and amines/ammonia are abundant (see above). Rather, the problem is high temperatures and high surface area. The question is under this conditions, the very low 0.1 ppt of DMA can make nucleation proceeding kinetically, without any other species?

Line 82: please cite You and Lee, EC, 2012; You et al., ACP 2014.

Line 88: clarify that Kirkby et al. Nature 2016 conclusion is based on CLOUD chamber studies, and this yet needs to be verified by atmospheric measurements, in pristine forests during the night, for example.

Line 137: indicate the detection limit and time resolution of the IC method used to detect amines.

Line 148: "time-rate-of-change"?

Printer-friendly version

Line 264: si,j?

Lines 320-327: what is the exact sulfuric acid background level (without $\mathrm{OH}$ )? Is it dependent on SO2 or temperature? Why do you have to discount that sulfuric acid? 
How did you know that is not "real" sulfuric acid?

Line 474: ke,A1b1=0.1, 1, 10(?) s-1?

Line 481: 40 or 20 ppt? (earlier it was mentioned as $20 \mathrm{ppt}$ ).

Line 497: 1 ppt DMA is still larger than $5 \mathrm{e} 6 \mathrm{~cm}-3$ sulfuric acid, so this is a base dominant environment. So, this is again quite different from the Jen-ACP-2016 condition.

Interactive

comment

Line 507: Why would you assume that Hytiala has low DMA around $0.1 \mathrm{ppt}$, because Cl-Api-TOF did not measured DMA? Remove.

Line 517: CS 2e-3 s-1 is very clean, compared to most of boundary layer conditions.

Line 527-535: why assume DMA is anti-correlated with $\mathrm{OH}$ (due to $\mathrm{OH}$ oxidation)? In fact, atmospheric measurements, even by the authors (Kurten et al., ACP 2016; Jen et al., GRL 2017) and others (You et al., ACP 2014; Yao et al., ACP 2016), consistently showed that amines have the same diurnal cycles as ambient temperatures, higher concentrations during the day than at night. This indicates that the main sink of amines in the atmosphere is condensation to aerosols, and not the oxidation by $\mathrm{OH}$ or photolysis (You et al., ACP 2014).

Lines 535-541: remove.

Lines 599-560: reword this conclusion here and at other places.

Line 560 and on: Please see Yu et al., JGR 2017 on RH effects on J and GR for sub-3 $\mathrm{nm}$ particles. Please cite this paper.

Line 564 and on: Please see Hanson et al., JPC 2017. Evaporation rates are highly dependent on thermodynamics data. Cite this.

Line 641: Zhao et al., 2014 - if I recall correctly, this cited study intentionally included excessively high sulfuric acid in the inlet of CIMS to see SA-DMA clusters, rather than directly measure the "existing" SA-DMA clusters from ambient air. (This is very similar 
to Jen et al. flow tube environment, where acid exceeds base. Interesting instrumentation mechanics, if compare cluster-CIMS vs. Cl-TOF ?)

Chen, H. and B.J. Finlayson-Pitts, New Particle Formation from Methanesulfonic Acid and Amines/Ammonia as a Function of Temperature. Environmental Science \& Technology, 2017. 51: p. 243-252.

Chen, H., M.E. Varner, R.B. Gerber, and B.J. Finlayson-Pitts, Reactions of Methanesulfonic Acid with Amines and Ammonia as a Source of New Particles in Air. The Journal of Physical Chemistry B, 2016. 120: p. 1526-1536.

Hanson, D.R., I. Bier, B. Panta, C.N. Jen, and P.H. McMurry, Computational Fluid Dynamics Studies of a Flow Reactor: Free Energies of Clusters of Sulfuric Acid with NH3 or Dimethyl Amine. The Journal of Physical Chemistry A, 2017. 121: p. 3976-3990.

Kürten, A., A. Bergen, M. Heinritzi, M. Leiminger, V. Lorenz, F. Piel, M. Simon, R. Sitals, A.C. Wagner, and J. Curtius, Observation of new particle formation and measurement of sulfuric acid, ammonia, amines and highly oxidized organic molecules at a rural site in central Germany. Atmos. Chem. Phys., 2016. 16: p. 12793-12813.

Yu, H., L. Dai, Y. Zhao, V.P. Kanawade, S.N. Tripathi, X. Ge, M. Chen, and S.-H. Lee, Laboratory observations of temperature and humidity dependencies of nucleation and growth rates of sub-3âĂL'nm particles. Journal of Geophysical Research: Atmospheres, 2017. 122: p. 1919-1929.

Interactive comment on Atmos. Chem. Phys. Discuss., https://doi.org/10.5194/acp-2017-636, 2017. 